rapidity of the action depends greatly on the freshness of the preparation of antitoxin. Forty-two out of the forty-three cases recovered without any serious symptoms.

StGeorge Reid.

\title{
MOUTH, \&G.
}

Gerhardt.-Mairoglossia. " Münchener Med. Woch.," Nov., I897.

THE author reports a case of macroglossia congenital in a child, who afterwards died from exhaustion, the hypertrophy interfering with nourishment. Two forms of macroglossia : (I) hypertrophy of connective tissue and muscle, and (2) hypertrophy of lymphatics and blood vessels.

Gleitsmann, J. W. - The Treatment of Chronic Affetions of the Faucial Tonsits; with Demonstration of Instruments. "New York Med. Journ.," Sept. 4, 1897.

IN chronic tonsillar inflammations characterized by the presence of a white exudate plugging the crypts on the surface, the author insists on thorough exposure of the whole of the diseased surface, and for this purpose speaks highly of a small so-called "palate hook," by means of which the anterior pillar is readily pushed aside. Mere removal of the exudates with subsequent applications is not sufficient ; the crypt must be enlarged to effectually prevent their re-formation. For this latter purpose the author was in the habit of using Moritz Schmidt's blunt hook, but, as the use of this instrument is often very painful, he has had its side sharpened, retaining its blunt tip. In another much rarer affection, where the tonsil is more or less extensively covered by a flap of a dense membranous formation, he has devised a tonsillar clipper for the removal of the latter. This instrument is a modification of Ruault's punch, the blades being reversed, and cutting in a horizontal instead of in a vertical plane.

Sandford.

Lewis, Robert. - Angio-neurosis of Tongue due to Afplication of Chromic Acid to Tympanic Membrane. " NNew York Med. Journ.," Oct. 9, 1897.

THE patient, a woman of forty-eight, was of average good health, not neurotic, and certainly with no hysterical tendency. She was suffering from left chronic otitis media for a number of years. The author cauterized with chromic acid some granulations on the upper and posterior parts of tympanic membrane, and about twelve hours after the application the patient's tongue began to swell rapidly, and for a few hours seriously embarrassed her breathing. The swelling, however, subsided after some hours. Six months later she again consulted the writer for the ear trouble, and chromic acid was again employed for the same purpose as before. In about twelve hours after her tongue, for the second time, began to swell, and to such an extent interfered with her respiration that a tracheotomy was seriously considered. The swelling, fortunately, yielded to milder measures. The case was evidently one of angio-neurotic œdema, and for various reasons the author feels warranted in concluding that the oedema must in some way be due to active stimulation of the chorda tympani nerve.

Sandford.

Raugé. - Traumatic Paralysis of the Soft Palate. " Arch. Intern. de Lar., Otol., et Rhinol.," Sept. and Oct., 1897.

THE case of a perfectly healthy man of fifty-nine, who accidentally fell, striking the side of the neck on the edge of a box. Consciousness was lost for about an hour, and, immediately on its return, the voice was found to have a nasal quality, and fluids were rejected through the nose on swallowing. There was slight 
epistaxis, but no hæmorrhage from the ear. There was no swelling or ecchymosis about the injured region. Pain was experienced behind and ower the left ramus of the jaw, and the head was turned with difficulty. Further examination showed the palate to be completely and symmetrically paralyzed. Sensibility of the parts was intact, but the palate reflex was entirely absent. There was no trace of paralysis of the facial or other muscles, with the exception of marked symmetrical hyperacusis, presumably due to interference with the tensor tympani or stapedius muscles. Besides the paralysis of the palate and the hyperacusis, no other symptoms were present-beyond some dryness of the mucous membrane and a questionable impairment of taste. The subsequent history is not given.

The author makes a critical inguiry into the traumatic nerve lesions which could posilly have producel these phenomena. He is unable to arrive at a definite conclusion, but suggests the prusibility of a circumscribed homorrhage in the anterior motor column, or a fracture of the petrous bone not involving the facial, but injuring the intermediary nerve of Weisberg.

Ernest Wagsett.

\section{N O SE, \&C.}

Breitung, Max (Coburg). - Foreign Body in the Nose. "Dentsche Med. Woch.," Nov. 18, I897.

Tine author reports a case of a boy, five years old, who had suffered for three months from loss of appetite, disturbed sleep, and a bloody purulent discharge from the nose. The skin over the nose and neighbouring part of the cheek was swollen, slightly reddened, and sensitive. The upper lip was ulcerated by the bloody, barl-smelling discharge. Nostril was completely blocked. Examination reveaied a mass covered with pus, which was removed with forceps. It proved to be a piece of flesh, which the author thinks must have been forced into the nose by coughing. Ie points out the danger of forcing pus into the ears in these cases by either inflation or syringing through the other nostril.

Bryan, J. H.-A Neoplasin of Nasal Fossa. "Proceedings of American Laryngological Association," May 4, 5, and 6, 1897. "New York Med. Journ.," Sept. 4 , I 897 .

THE patient, a man of twenty year, had for several years complained of symptoms of nasal olstruction. These were lue to a growth in the left nostril, causing some projection externally of the nasal bone, and extending back into the naso-pharynx and occluling the left posterior nares entirely, and partly alen the right. Proptosis was alio jresent on the left side, and the tumour bled frecly on the least interference. Several unsuccesful attempts were made by the author to remove it ly the galvanic snare. The precise origin of the growth could not be determined, and it was suggested it might spring from the antrum of Highmore. As to its nature, there was also some divergence of opinion, and microscopic examination failed to decide between a fibroma undergoing inflammatory change and a fibro-sarcoma. It was agreed that naso-pharyngeal growths are more often of a benign character, but the doubtful origin of the tumour under consideration rendered such reasoning of little moment. Dr. Simpson was inclined to regard the case as "inoperable," while others (Solis-Cohen) suggester extirpation after access by Rouge's operation. The case affordefl a very appropriate occasion to insist on the necessity of early diagnosis and radical operative procedure in cases of actual or suspected malignant growths in this region.

Sandford. 